\title{
Dynamometer Tests to Estimate Efficiencies of Slow Moving Vehicles
}

\author{
Harwin Saptoadi \\ Dept. of Mechanical and Industrial Engineering, Universitas Gadjah Mada, Indonesia
}

\begin{abstract}
City cars are expected to be green and fuel saving. However, due to crowded urban traffic they must move slower and thus less efficient. Vehicle efficiency has to be quantitatively revealed. A chassis dynamometer is used for the purpose. Two important parameters, e.g. fuel consumption and car efficiency, can be predicted successfully. The results agree well with the real condition. It is apparent that driving with lower velocity consumes less fuel, however the efficiency will be very poor. At the velocity of $10 \mathrm{~km} / \mathrm{h}$ the efficiency will be only $5.74 \%$, which represents fuel energy wastage of around $94.26 \%$. The best efficiency for the first gear position is only about $14.9 \%$. In order to get higher efficiency the driver should upswitch to the second gear as soon as the traffic condition allows him to speed up to $30 \mathrm{~km} / \mathrm{h}$. The efficiency for the second gear can attain $24.9 \%$, which is quite common and reasonable for gasoline fueled cars. Based on the calculation results, two 3-order polynomials have been developed to estimate fuel consumption and efficiency at low speeds, i.e. less than 35 $\mathrm{km} / \mathrm{h}$, i.e. $\dot{m}_{f}=-610^{-4} \mathrm{~S}^{3}+0.0482 \mathrm{~S}^{2}-0.8816 \mathrm{~S}+11.275$ and $\eta_{C}=1.94410^{-3} \mathrm{~S}^{3}-0.1649 \mathrm{~S}^{2}+4.4714 \mathrm{~S}-$ 24.277. These equations almost accurately represent the reality.
\end{abstract}

Keywords: Car speed, Dynamometer test, Efficiency, Fuel consumption, Gear position.

\section{Introduction}

Small sized cars are purposely introduced as appropriate solution for heavy urban traffics, mostly due to its better maneuverability. They are gasoline fuelled with cylinder volume of only 1 liter or even less. These city cars are expected to be green and energy-saving, because essentially smaller cars require less fuel and hence release fewer gas emissions compared to normal vehicles. In the reality, streets are now occupied by city cars, as they become affordable even to middle class families in Indonesia. Traffic congestions occur more frequently and intolerably, particularly during rush hours, which will waste fuels uselessly and emit more greenhouse gas, especially carbon dioxide. Even when no traffic jam happens, vehicles must move with lower speed. Unexpectedly, city cars become less efficient in urban traffics. Efficiency is defined as the ratio of power available in the wheels to move the vehicle to the energy supplied by the fuel. Therefore, reducing fuel consumption may lead to efficiency improvement. Sometimes an almost equivalent term, fuel economy (in mile/gallon or $\mathrm{km} / \mathrm{l}$ ), is used to denote efficiency.

A theoretical calculation has been carried out to show quantitatively how low speed city cars perform negatively when they go through traffic congestions. The higher the traffic density, the more the aggregated fuel consumption and gas emission. In a normal traffic, e.g. 50 cars per kilometer road length and all are ready to decelerate at least $3 \mathrm{~m} / \mathrm{s}^{2}$, the total fuel usage amounts to not more than $2.51 / \mathrm{km}$. On another case, if there are already 95 cars occupying one kilometer road length and the drivers can decelerate only at $1 \mathrm{~m} / \mathrm{s}^{2}$, they consume totally around $8.5 \mathrm{l} / \mathrm{km}$, which is more than three folds [1]. However, experimental measurements using a chassis dynamometer would be more realistic, as commonly carried out since decades. For example, Moskalik et al. determines the efficiency and operation of vehicle driveline components of a 2.5 liter naturally aspirated gasoline engine with 6-speed automatic transmission and a 3 liter turbodiesel engine with 7-speed automatic 
transmission. Their experiments can construct efficiency maps for both engines and transmissions. Efficiencies between $5 \%$ and $35 \%$ are reported, which depend on engine rotational speeds and torques. The gasoline engine substantially produces lower torques but higher speeds than that of diesel engine [2]. HEVs (Hybrid Electric Vehicles) and diesel trucks are tested on a chassis dynamometer as well. The results show that normally HEVs have between $25 \%-31 \%$ better fuel economy than diesel vehicles. Basically, higher vehicle speeds of both types will yield better fuel economy, e.g. 4.6 mile/gallon will increase to 8.5 mile/gallon (for diesel trucks) and $6.75 \mathrm{mile} / \mathrm{gallon}$ will increase to $8.2 \mathrm{mile} / \mathrm{gallon}$ (for HEVs). The mentioned lower fuel economy is achieved at 13 mile/hour, whereas the higher one at 36 mile/hour [3].

Another research deals also with measurements on a dynamometer test bed and simple calculations in order to show the phenomenon quantitatively. The most fuel-efficient operations (around 10 1/km) are achievable at traffic densities less than 60 cars per km road length, when the cars use third gear. Moderate fuel consumptions (14 - $22 \mathrm{l} / \mathrm{km}$ ) come about at traffic densities less than $80 \mathrm{car} / \mathrm{km}$, if the gear is switched from first to second. Running at the first gear, due to low velocities at traffic densities more than $80 \mathrm{car} / \mathrm{km}$, make fuel inefficiency occur (up to $61.6 \mathrm{l} / \mathrm{km}$ ). Higher gear shifting can considerably help reducing fuel wastage. Finally, simple mathematical formulas are proposed to estimate aggregated fuel consumption and total $\mathrm{CO}_{2}$ emission as a function of traffic densities at various gear positions [4]. A vehicle with 3.6 liter engine is tested on a chassis dynamometer in order to estimate its fuel consumption and efficiencies, i.e. engine and drivetrain efficiencies. As commonly presumed, there are considerable differences between city and highway cycles. The average fuel consumption using five-speed transmission during city cycle is $21.45 \mathrm{mile} / \mathrm{gallon}$, whereas that with eight-speed transmission amounts to $22.79 \mathrm{mile} /$ gallon. On the other side, the average fuel consumption using 5 -speed transmission in highway cycle reaches 37.04 mile/gallon, whereas that with 8-speed transmission attains 40.11 mile/gallon. Moreover, the engine efficiency using 5-speed transmission during city cycle is $20.6 \%$, whereas that with 8 -speed transmission amounts to $21.4 \%$. The drivetrain efficiency using 5 -speed transmission during city cycle is $69.6 \%$, whereas that with 8 -speed transmission amounts to $72.3 \%$. Generally, those efficiencies are improved about $4 \%$ when the vehicle is operated at the highway cycle [5].

Kim et al. use a chassis dynamometer for measuring emission from a 2-liter engine of the most popular passenger car in Korea, meanwhile the engine performance, such as rotational speed, torque and fuel consumption, is investigated by employing an engine dynamometer. They find out that lower fuel consumption (between 3.41 and $3.63 \mathrm{~kg} / \mathrm{h}$ ) is achieved at lower engine speed, i.e. $2000 \mathrm{rpm}$. At $3000 \mathrm{rpm}$ the requirement gets higher $(5.26-5.54 \mathrm{~kg} / \mathrm{h})$ and finally at $4000 \mathrm{rpm}$ it becomes even more (between 7.54 and $7.94 \mathrm{~kg} / \mathrm{h}$ ) [6]. However the results do not reflect the actual fuel consumption on the streets because the test excludes transmission system which transfers generated power from the engine to wheels.

\section{Research Methodology}

A commonly found small car is selected to undergo several tests by running it statically on an AWD 1200 chassis dynamometer. It is a sedan with 1-liter gasoline engine, which consists of 3 cylinders, 12 valves, DOHC, EFI and 5-speed manual transmission. The dynamometer has maximum rated power of $850 \mathrm{~kW}$ per axle at 240 $\mathrm{km} / \mathrm{h}$ and rated torque of $1,700 \mathrm{Nm}$ per bed. It has an adjustable wheel base between $230 \mathrm{~cm}$ and $325 \mathrm{~cm}$, and also track widths of $60 \mathrm{~cm}-220 \mathrm{~cm}$, as shown in Fig 1.

The dynamometer tests can deliver engine performance diagrams, such as torques, powers and AFR (air-fuel ratio) at various engine rotational speeds $\mathrm{N}$ (and their corresponding vehicle speeds $\mathrm{S}$ ) and gear positions. An almost similar procedure can be found elsewhere [4].

The fuel consumption $\dot{m}_{f}$ is calculated with the help of the measured AFR, which is

$$
A F R=\frac{m_{a}^{i}}{m_{f}},
$$

and the air consumption $\dot{m}_{\alpha}$ is calculated with the help of the equation

$$
\dot{m}_{a}=\eta_{\mathrm{V}} \rho_{\mathrm{a}} \mathrm{V}_{\mathrm{d}} \frac{\mathrm{N}}{2} \text {, }
$$

whereas $\eta_{\mathrm{V}}$ is volumetric efficiency, $\rho_{\mathrm{a}}$ is air density, $\mathrm{V}_{\mathrm{d}}$ is piston displacement, $\mathrm{N}$ is the rotational speed, and the number 2 indicates that there are 2 engine rotations for one air intake. The volumetric efficiency $\eta_{\mathrm{V}}$ actually fluctuates between $0.8-0.89$ with engine speeds, therefore an assumed constant value of 0.86 is acceptable [7]. The air density $\rho_{\mathrm{a}}=1.1321 \mathrm{~kg} / \mathrm{m}^{3}$, because the ambient condition is $32{ }^{\circ} \mathrm{C}$ and $991 \mathrm{mbar}$. 


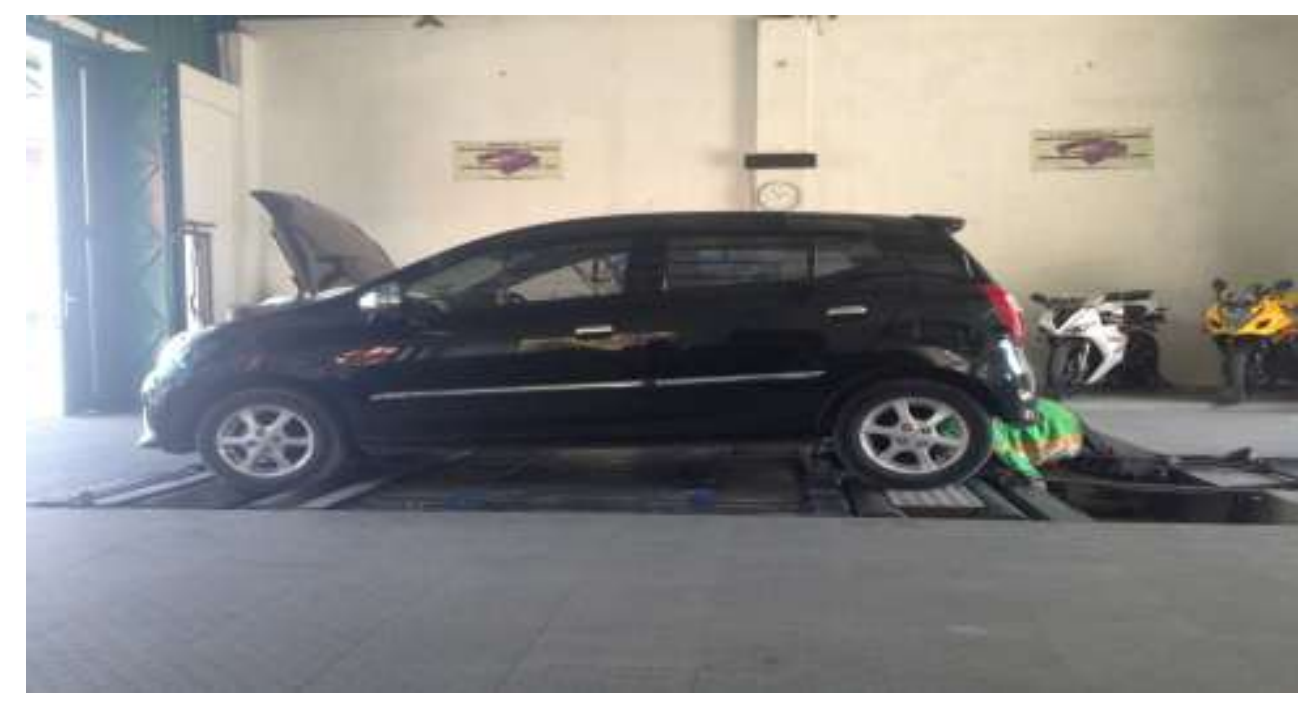

Fig. 1: The Tested Car on the Chassis Dynamometer

Finally, the car efficiency $\eta_{C}$ at different speeds can be estimated using the equation

$$
\eta_{\mathrm{C}}=\frac{\text { Power }}{m_{f} L H V} \text {, }
$$

whereas the lower heating value LHV of Pertamax, a commonly marketed gasoline in Indonesia, is 10,575 $\mathrm{cal} / \mathrm{g}$ or $44,245 \mathrm{~kJ} / \mathrm{kg}$ [8]. The vehicle power is obtained from the dynamometer tests. Calculations using those three equations are based on car speed $S$ ranges from $10 \mathrm{~km} / \mathrm{h}$ and $35 \mathrm{~km} / \mathrm{h}$ (for the first gear), and subsequently between $30 \mathrm{~km} / \mathrm{h}$ and $40 \mathrm{~km} / \mathrm{h}$ (for the second gear). A constant interval of $5 \mathrm{~km} / \mathrm{h}$ is used in the computations.

\section{Results and Discussions}

The results of the dynamometer measurements are revealed in Figure 2 . Data from the $3^{\text {rd }}, 4^{\text {th }}$ and $5^{\text {th }}$ gears are intentionally excluded because they are applied only for high car velocities (more than $40 \mathrm{~km} / \mathrm{h}$ ).

All engines have such similar characteristics that maximum power and torque exist at certain engine rotational speeds. Initially both power and torque increase with engine speed $\mathrm{N}$ (and car speed $\mathrm{S}$ as well) and then both will decline. At the $1^{\text {st }}$ gear position, the maximum torque $(43.33 \mathrm{Nm})$ and power $(31.5 \mathrm{HP})$ are achieved concurrently at $6224 \mathrm{rpm}(34 \mathrm{~km} / \mathrm{h})$, while the corresponding AFR changes only slightly above 14 at most speeds. After the speed $\mathrm{S}$ of $30 \mathrm{~km} / \mathrm{h}$ is attained, the driver can switch the gear up to the $2^{\text {nd }}$ position, where the maximum torque $(66 \mathrm{Nm})$ occurs at $4348 \mathrm{rpm}(46 \mathrm{~km} / \mathrm{h})$ and the highest power $(52.3 \mathrm{HP})$ is attained at 6210 $\mathrm{rpm}(68 \mathrm{~km} / \mathrm{h})$. The related AFR varies around 13 at speeds lower than $40 \mathrm{~km} / \mathrm{h}$.

The fuel consumptions $\dot{m}_{f}$ are obtained using Equations 1 and 2, along with data from Figure 2, while the car efficiency $\eta_{\mathrm{C}}$ are calculated with the help of Equation 3 and Figure 2. The results of both are displayed in Figure 3. The number in parenthesis, either 1 or 2 (see the legend), denotes the gear position.

Just like many other cars, higher speeds require more fuel to generate enough power to overcome consequently higher aerodynamics drag, rolling and acceleration resistances. It seems that there is no optimum speed for minimum fuel consumption. It is obvious that $6.65 \mathrm{~kg} / \mathrm{h}$ of gasoline is consumed at $\mathrm{S}=10 \mathrm{~km} / \mathrm{h}$, then more fuel is spent at higher speed, and finally at $S=35 \mathrm{~km} / \mathrm{h}$ the required amount is more than doubled (13.6 $\mathrm{kg} / \mathrm{h}$ ). However, if the driver at $30 \mathrm{~km} / \mathrm{h}$ switches the gear up higher, he can considerably cut the fuel usage from $12.17 \mathrm{~kg} / \mathrm{h}$ to its half $(6.3 \mathrm{~kg} / \mathrm{h})$. The advantage of switching up the gear is more apparent at $35 \mathrm{~km} / \mathrm{h}$, where the fuel expense becomes only $57 \%$, from $13.6 \mathrm{~kg} / \mathrm{h}$ down to $7.77 \mathrm{~kg} / \mathrm{h}$. 

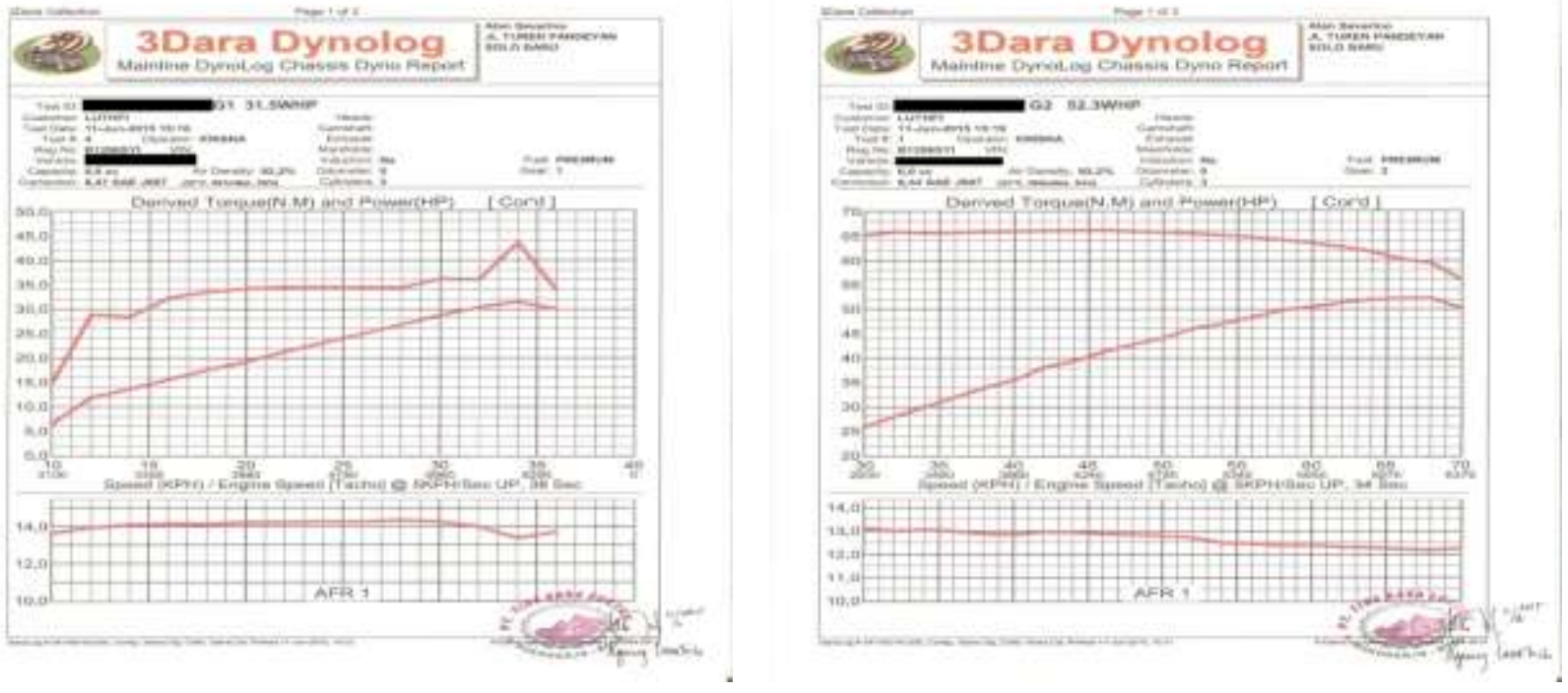

Fig. 2: Results at $1^{\text {st }}$ gear (left) and $2^{\text {nd }}$ gear (right)

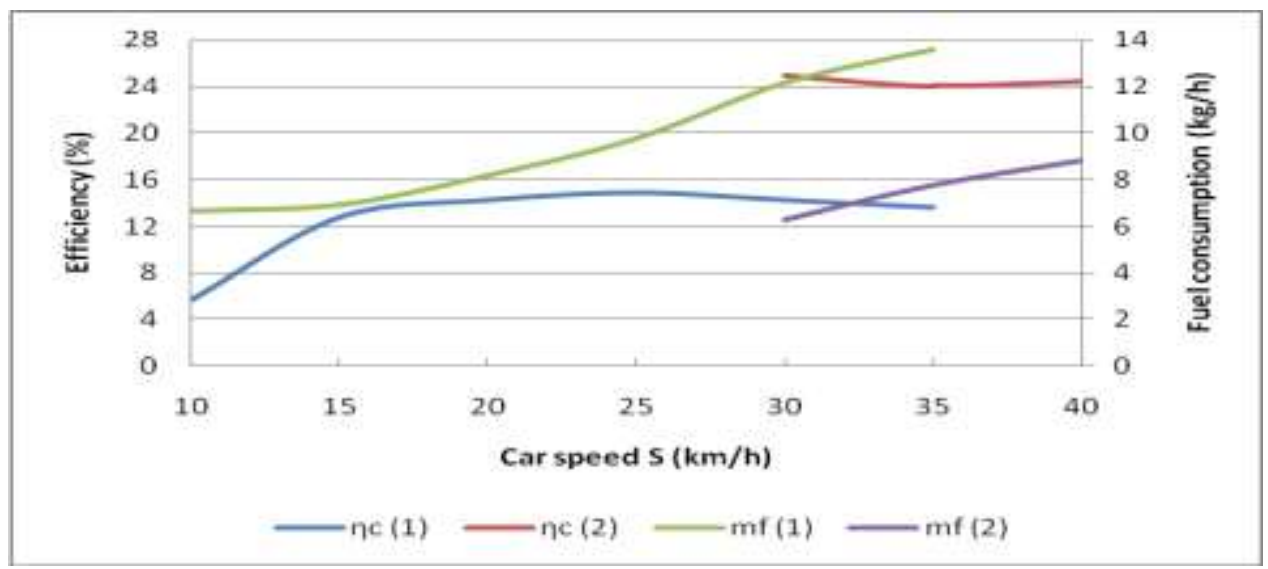

Fig. 3: Fuel Consumption and Car Efficiency At Various Vehicle Speeds.

On the contrary, there is a maximum vehicle efficiency and thus an optimum speed $S_{\text {opt }}$, especially for the first gear position. The phenomenon is attributed to the vehicle power which has a peak. However, it is observed that the peak efficiency does not occur at the same speed as the peak power. The efficiency starts from as low as $5.74 \%$ at $10 \mathrm{~km} / \mathrm{h}$ to its utmost, i.e. $14.91 \%$, at $\mathrm{S}_{\mathrm{opt}}=25 \mathrm{~km} / \mathrm{h}$, and then declines gradually afterward. Therefore it is advisable to move forward with $25 \mathrm{~km} / \mathrm{h}$ if the first gear is engaged. However, if $30 \mathrm{~km} / \mathrm{h}$ is achievable, it is better to switch up the gear because the efficiency will increase sharply from $14.25 \%$ to $24.9 \%$. At higher speeds (and at the second gear) the efficiency will be almost constant.

Actually, the minimum estimated efficiency of $5.74 \%$ is particularly disappointing. It means that around $94 \%$ of fuel energy is wasted uselessly by very slow moving cars. Such a poor efficiency likely happens at low torques [2]. Unless the gear is upshifted, the maximum efficiency will be kept low (less than 15\%), which has been predicted previously by Moskalik et al. [5], who realizes an engine efficiency of around $20 \%$ and transmission efficiency of about $70 \%$. Only after the second gear is applied (at speed $\geq 30 \mathrm{~km} / \mathrm{h}$ ) a better efficiency of about $25 \%$ is achieved. The value is quite acceptable, since actual gasoline fueled cars have efficiency ranges from $25 \%$ to $30 \%$ [9]. The efficiency improvement by switching up the gear is attributed to the rotational speed reduction and torque increase, which moves the operational condition to better position in the efficiency maps [2]. The upshifting makes the engine operate closer to its peak efficiency [5]. 
Based on the data shown in Figure 3, two simple third-order polynomials can be developed as an approximation to the fuel consumption $\dot{m}_{f}$ and car efficiency $\eta_{C}$ as a function of car speed S. See the following equations 4 and 5. Nevertheless, those equations are only for the first gear, where the speed varies between $10 \mathrm{~km} / \mathrm{h}$ and $35 \mathrm{~km} / \mathrm{h}$. Unfortunately, there are no such equations for the second gear due to lack of data.

$$
\begin{aligned}
& \dot{m}_{f}=-610^{-4} \mathrm{~S}^{3}+0.0482 \mathrm{~S}^{2}-0.8816 \mathrm{~S}+11.275 \\
& \eta_{\mathrm{C}}=1.94410^{-3} \mathrm{~S}^{3}-0.1649 \mathrm{~S}^{2}+4.4714 \mathrm{~S}-24.277
\end{aligned}
$$

\section{Conclusions}

Chassis dynamometer has capability to simulate vehicle operation and estimate its performance, such as torque, power and AFR. With some additional calculations, other important parameters, e.g. fuel consumption and car efficiency, can be predicted successfully. The results agree well with the real condition. In spite of lower fuel consumption, slow driving is unfavorable even for small-sized cars because their efficiencies will be very poor. At the velocity of $10 \mathrm{~km} / \mathrm{h}$ the efficiency will be only $5.74 \%$, which represents fuel energy wastage of around $94.26 \%$. The maximum efficiency for the first gear position is only about $14.9 \%$ at $25 \mathrm{~km} / \mathrm{h}$, therefore the driver should upswitch to the second gear as soon as the traffic condition allows him to speed up to $30 \mathrm{~km} / \mathrm{h}$. The efficiency for the second gear can attain $24.9 \%$, which is quite common and reasonable for gasoline fueled cars. The upshifting helps engines to operate closer to their peak efficiency. Two 3-order polynomials have been developed to estimate fuel consumption and efficiency at low speeds, i.e. less than $35 \mathrm{~km} / \mathrm{h}$. The equations almost accurately represent the reality.

\section{Acknowledgements}

The author would like to highly appreciate his excellent research assistant, Luthfi Isyraqi Milzam. Moreover, he gratefully thanks the Department of Mechanical and Industrial Engineering, Universitas Gadjah Mada, for funding the research in the fiscal year 2016 with the contract no. 1570/H1.17/TMI/LK/2016.

\section{References}

[1] H. Saptoadi, "Rebound effect of LCGC (low cost green car): Theoretical approach," in AIP Conference Proceedings 1755, 110001, International Conference on Science and Technology, Yogyakarta, 11-12 November 2015 (doi: 10.1063/1.4958535), 2016. https://doi.org/10.1063/1.4958535

[2] A. Moskalik, P. Dekraker, J. Kargul, and D. Barba, "Vehicle component benchmarking using a chassis dynamometer," SAE International Journal of Materials and Manufacture 8 (3), doi: 10.4271/2015-01-0589, 2015. https://doi.org/10.4271/2015-01-0589

[3] J. Burton, K. Walkowicz, P. Sindler, and A. Duran, "In-use and vehicle dynamometer evaluation and comparison of class 7 hybrid electric and conventional diesel delivery trucks," SAE International Journal of Commercial Vehicles 6 (2), doi: 10.4271/2013-01$2468,2013$. https://doi.org/10.4271/2013-01-2468

[4] H. Saptoadi, "Entropy principles in dense urban traffics," in Proceedings of the $9^{\text {th }}$ ASEAN Civil Engineering conference, Brunei Darussalam, 14-15 November 2016.

[5] A. Moskalik, A. Hula, D. Barba, and J. Kargul, "Investigating the effect of advanced automatic transmissions on fuel consumption using vehicle testing and modeling," SAE International Journal of Engines 9 (3), doi: 10.4271/2016-01-1142, 2016. https://doi.org/10.4271/2016-01-1142

[6] D.H. Kim, J.M. Lee, E.H. Park, J.H. Song, and S.I. Park, "Engine performance and toxic gas analysis of biobutanol-blended gasoline as a vehicle fuel," International Journal of Automotive Technology vol. 12, no. 3, pp. 409-416, doi: 10.1007/s12239-011-0048-2, 2011. https://doi.org/10.1007/s12239-011-0048-2

[7] A.H. Shamekhi, N. Khatibzadeh, and A. Shamekhi, "A comprehensive comparative investigation of CNG as an alternative fuel in a bi-fuel spark ignition engine," Iranian Journal of Chemistry and Chemical Engineering, vol. 27, no. 1, pp. 73 - 83, 2008.

[8] R. Irzon, "Perbandingan calorific value beragam bahan bakar minyak yang dipasarkan di Indonesia menggunakan bomb calorimeter," Jurnal Sumber Daya Geologi, vol. 22, no. 4, pp. 217-223, ISSN: 1829-5819, 2012.

[9] Y.A. Cengel, and M.A. Boles, Thermodynamics : An engineering approach, $5^{\text {th }}$ edition, McGraw-Hill, 2006 , ch. 8, p. 461. 